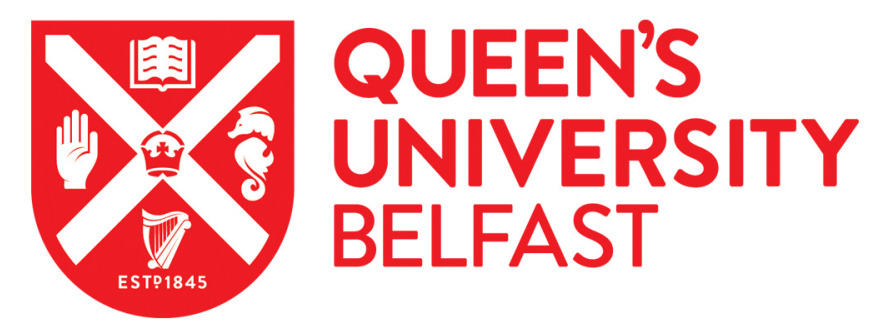

\title{
Experimental Characterisation of Near Field Backscatter from Thin Resistively Loaded FSS Absorbers
}

McGuigan, N., Conway, G., Cahill, R., Zelenchuk, D., \& Zabri, N. (2017). Experimental Characterisation of Near Field Backscatter from Thin Resistively Loaded FSS Absorbers. IET Electronics Letters, 1-2. https://doi.org/10.1049/el.2017.3233

\section{Published in:}

IET Electronics Letters

\section{Document Version:}

Peer reviewed version

Queen's University Belfast - Research Portal:

Link to publication record in Queen's University Belfast Research Portal

\section{Publisher rights}

( ) Institution of Engineering and Technology. This work is made available online in accordance with the publisher's policies. Please refer to any applicable terms of use of the publisher.

\section{General rights}

Copyright for the publications made accessible via the Queen's University Belfast Research Portal is retained by the author(s) and / or other copyright owners and it is a condition of accessing these publications that users recognise and abide by the legal requirements associated with these rights.

Take down policy

The Research Portal is Queen's institutional repository that provides access to Queen's research output. Every effort has been made to ensure that content in the Research Portal does not infringe any person's rights, or applicable UK laws. If you discover content in the Research Portal that you believe breaches copyright or violates any law, please contact openaccess@qub.ac.uk. 


\section{Experimental Characterisation of Near Field Backscatter from Thin Resistively Loaded FSS Absorbers}

\author{
N. McGuigan, G. Conway, R. Cahill, D. Zelenchuk and \\ S. Zabri
}

Experimental results are employed to show that a thin metal backed resistively loaded Frequency Selective Surface (FSS) exhibits significant radar backscatter suppression when the structure is illuminated by an antenna placed in close proximity to the periodic array. This is investigated in the range $9-11 \mathrm{GHz}$ by measuring the shift in the resonant frequency of an impedance matched $\left(\left|\mathrm{S}_{11}\right| \sim 15 \mathrm{~dB}\right.$ at $10.22 \mathrm{GHz}$ ) microstrip patch which is placed in five different positions ranging from $\lambda / 30$ to $\lambda / 5$ distance above the surface of the FSS. Detuning of the antenna by signals reflected from the absorber surface is shown to be much less significant than the upward frequency shift in the measured $\left|S_{11}\right|$ for a metal plate and tissue phantom, therefore this technology could be used to enhance the performance of on-body wireless sensors.

Introduction: Thin radar absorbing materials (RAM) based on metal backed resistively loaded FSS [1]-[3], are an attractive option for reducing the radar crossection of aircraft, vehicle surfaces and wind turbines. The deployment of this class of RAM has the potential to satisfy the thickness, weight and shaping requirements which are imposed by other more fundamental design drivers such as the operating environment or aerodynamics. The operation of the absorber can be explained by using an equivalent circuit model to represent the $\mathrm{L}, \mathrm{C}, \mathrm{R}$ circuit of the FSS, which is connected in parallel to the inductance $L^{\prime}$ that is obtained from the transformed impedance of the metal sheet placed behind the periodic array [1]. A perfect impedance match to free space ( $377 \Omega$ ) is obtained when the imaginary part of the FSS impedance and L' cancel each other, and by suitable choice of R which is used to model the loss of the FSS array. To meet these criteria, the size, shape and surface resistance values of the resonant elements in each unit cell, and the separation distance between the FSS and metal ground plane are critical design factors. Recently there has been significant interest in developing new techniques for increasing bandwidth [1], [4], and reducing sensitivity to polarisation and angle of incidence [5]. These published studies, which are based on numerical simulations and measurements, assume that the FSS absorber is placed in the far field of the single (monostatic) or two (bistatic) antennas that are used to illuminate and detect the backscattered signals. Plane wave excitation of the structure is very close to reality for the intended applications mentioned above. By contrast, the purpose of this letter is to report the electromagnetic behaviour of a thin resistively loaded FSS absorber when the excitation antenna is placed very close $(\lambda / 30$ to $\lambda / 5)$ to the surface of the periodic array. To demonstrate that the structure exhibits high radar backscatter suppression, the monostatic response is compared with experimental data obtained for a similar size metal sheet and tissue equivalent phantom in the frequency range $9-11 \mathrm{GHz}$. The results are used to show that this class of RAM is suitable for applications in near field environments such as wearable systems, which require a low profile solution for decoupling antennas from lossy high permittivity tissue.

Design of FSS absorber and experimental set-up: The design of the $3 \mathrm{~mm}$ thick metal backed resistively loaded quadruple hexagonal loop FSS absorber was reported by the authors in [4], with measured reflectivity plots presented in the far field over the frequency range 7.8 $24 \mathrm{GHz}$. Although the dimensions of the periodic array used in this study are the same (Fig. 1(a) in [4]), a different manufacturing technique, based on ink-jet printing [6], [7], was employed to pattern the hexagonal loops on a $0.14 \mathrm{~mm}$ thick Novelle IJ-220 substrate [8]. This was found to produce loops with a surface resistance much closer to the design value of $27 \Omega / s q$, and thus give much better agreement with the computed reflectivity plot at normal incidence (Fig. 2(a) in [4]). The measured and simulated reflectivity in the far field is $12 \mathrm{~dB}$ at $10 \mathrm{GHz} .\left|\mathrm{S}_{11}\right|$ measurements were made using an Agilent PNA E8361C in conjunction with a computer controlled $\mathrm{X}, \mathrm{Y}, \mathrm{Z}$ CNC router machine

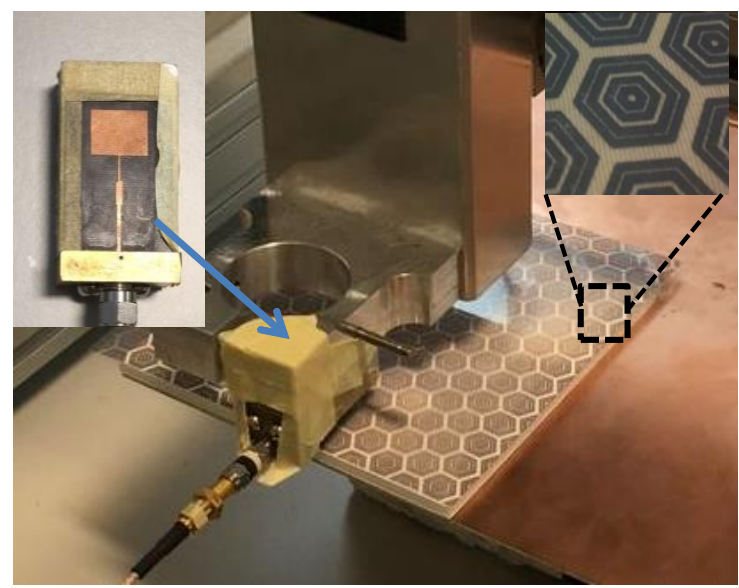

Fig. 1 Photograph of the $15 \times 15 \mathrm{~cm}^{2}$ resistively loaded FSS absorber placed in the 3D scanner. Inset plots show the microstrip patch antenna (radiating aperture facing FSS), and one unit cell of the FSS.

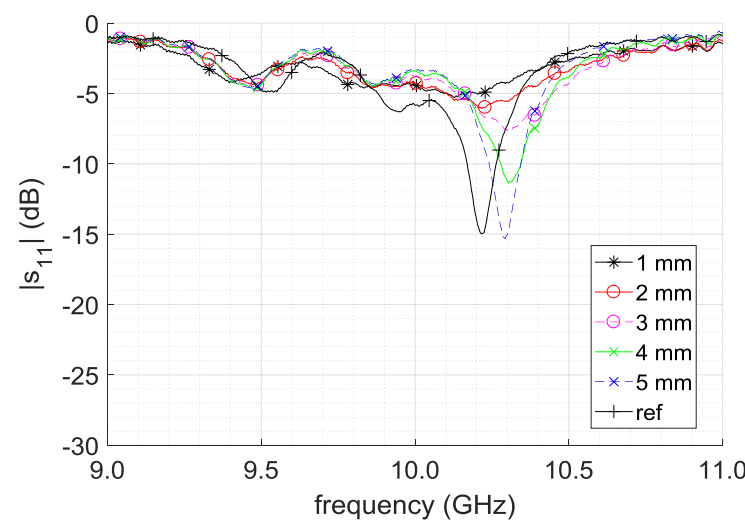

$a$

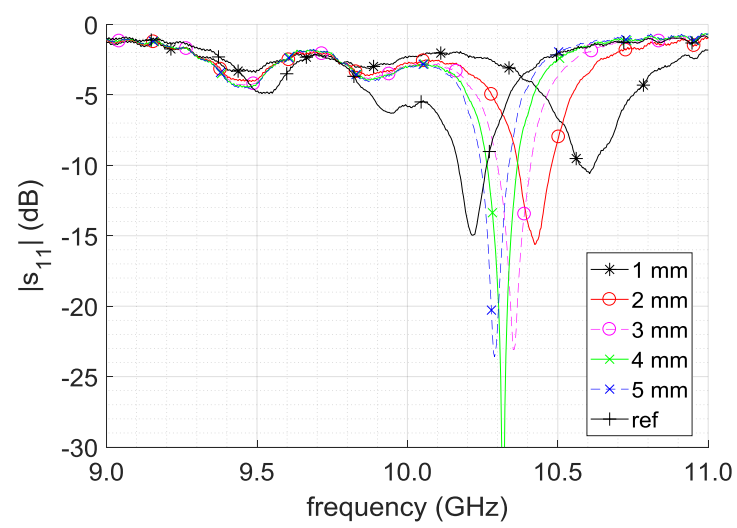

$b$

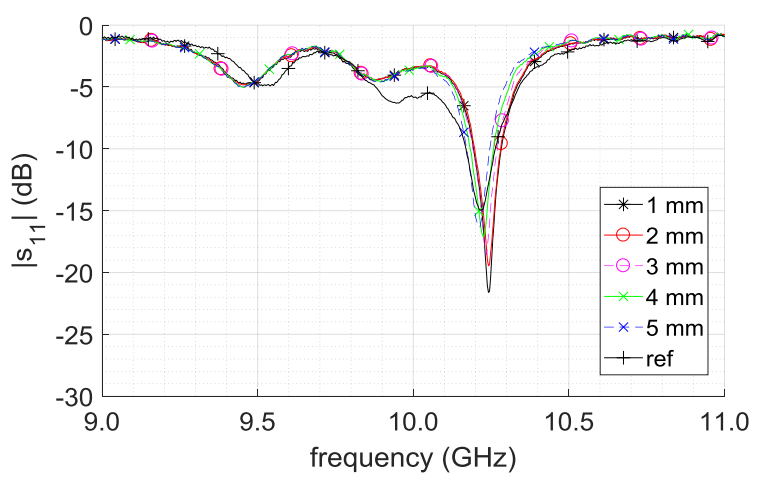

$c$

Fig. 2 Measured reflection coefficients for antenna/absorber separation distances of 1, 2, 3, 4 and $5 \mathrm{~mm}$. Ref is $\left|S_{I 1}\right|$ for antenna in free space. (a) tissue equivalent phantom, (b) metal sheet and (c) FSS absorber. 
with a repetition precision of $0.02 \mathrm{~mm}$. Each of the $15 \times 15 \mathrm{~cm}^{2}$ surfaces was fixed to the flat table of the 3D scanner and the antenna secured to the moveable vertical arm as illustrated in Fig. 1. The $12.2 \times$ $9.5 \mathrm{~mm}$ microstrip patch was printed on a $0.254 \mathrm{~mm}$ thick RT/Duroid 5880 microwave laminate with permittivity of 2.2 and loss tangent 0.0009 . Two quarter wavelength transformers were employed to provide a good impedance match to the $50 \mathrm{Ohm}$ input port.

Experimental results: Fig. 2 shows that the resonant frequency of the antenna in isolation is $10.22 \mathrm{GHz}$ (ref plots), at which the return loss is $15 \mathrm{~dB}$. The monostatic responses obtained for a phantom (measured average wrist $\varepsilon_{\mathrm{r}}=13, \sigma=1.2 \mathrm{Sm}^{-1}$ ), a metal (copper) plate and the FSS absorber were measured with the antenna placed $1(\lambda / 30), 2,3,4$, and 5 $\mathrm{mm}$ above the surface of the materials under test. Radar backscatter from these structures manifests itself as a frequency shift in the $\left|S_{11}\right|$ resonance of the well matched antenna. The motivation for this work was to investigate the feasibility of deploying thin FSS absorbers in the near field, to enhance the performance of wearable antennas by reducing the effect of the human body. The problem is illustrated in Fig. 2(a), which shows that scattering from the phantom produces an upward shift in the resonant frequency of the antenna, and for separation distances of $1 \mathrm{~mm}$ and $2 \mathrm{~mm}$ there is a significant reduction in the reflectivity minima. At the design frequency of the antenna (10.22 $\mathrm{GHz}$ ), the measured $\left|\mathrm{S}_{11}\right|$ is reduced to $5-7 \mathrm{~dB}$. Replacing the phantom with a metal plate produces deeper reflectivity nulls and in some cases a larger frequency shift which further reduces $\left|S_{11}\right|$ to $2-6 \mathrm{~dB}$ as depicted in Fig. 2(b). For $1 \mathrm{~mm}$ spacing, the resonant frequency increases by 420 $\mathrm{MHz}$ (4\%), but for larger separations, as expected, the reflectivity null approaches the frequency of the antenna in isolation. By contrast almost no detuning of the $\left|S_{11}\right|$ plots is observed in Fig. 2(c) for the polarisation independent FSS absorber, thereby confirming that this structure, which was designed for far field operation [4], does indeed provide significant backscatter suppression when the antenna is placed very close to the surface of the periodic array. For all five measurements, $\left|S_{11}\right|$ is shown to be $-15 \mathrm{~dB}$ at the design frequency of the microstrip patch and a shift of only $50 \mathrm{MHz}$ is observed when the separation distance is decreased from $\lambda / 5$ to $\lambda / 30$. As a general observation similar insensitivity was found when the monostatic response was sampled at discrete points over a distance of several unit cells in the $\mathrm{X}$ and $\mathrm{Y}$ plane, for each of the five $\mathrm{Z}$ positions. Fig. 3 shows a comparison between the measured $\left|S_{11}\right|$ response of the antenna placed $4 \mathrm{~mm}$ above the surface of the phantom and the metal plate, which if inserted would provide electromagnetic shielding. At the center operating frequency of the antenna, $\left|S_{11}\right|$ is reduced from $-15 \mathrm{~dB}$ to $-7 \mathrm{~dB}$ and $-6 \mathrm{~dB}$ respectively. However, for the $3 \mathrm{~mm}$ thick absorber with the antenna placed $1 \mathrm{~mm}$ above the $0.14 \mathrm{~mm}$ thick FSS layer to maintain the same overall thickness, it is observed that the reflectivity $(-15 \mathrm{~dB} / 10.22 \mathrm{GHz})$ of the antenna in isolation is regained. The performance change which occurs when the thin periodic layer is inserted above the metal ground plane is illustrated by comparing the plots for 'Copper' and 'Absorber' in Fig. 3. Moreover, the results depicted in Fig. 2 show that the enhancement would be even more significant for thinner structures.

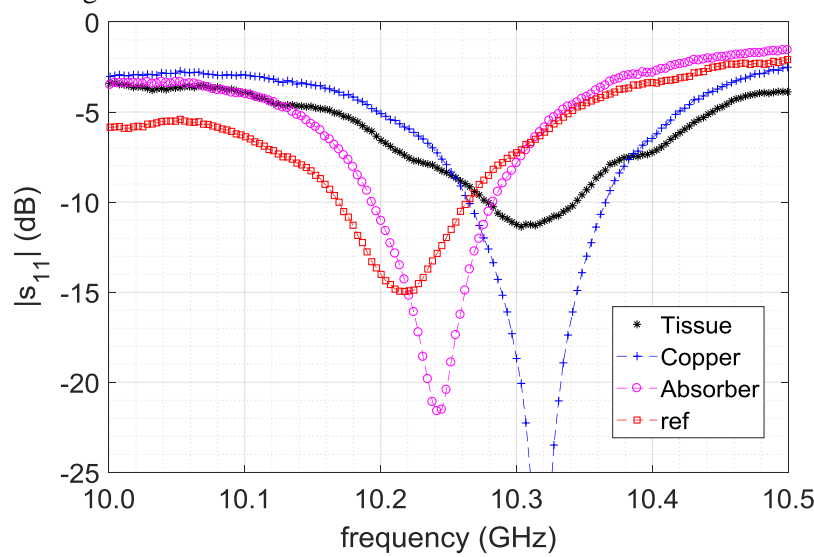

Fig. 3 Measured reflection coefficients for antenna placed $4 \mathrm{~mm}$ above the phantom and metal ground plane, and $1 \mathrm{~mm}$ above the surface of the $3 \mathrm{~mm}$ thick FSS absorber. Ref is antenna in free space.
Conclusion: An important outcome from this work is the demonstration that thin metal backed resistively loaded FSS absorbers designed to work in the far-field, also exhibit significant suppression of microwave radiation when the source antenna is placed very close to the structure. This opens up new possibilities for deployment in near field environments such as wearable systems, where poor radiation efficiencies and detuning are a significant problem. This is further compounded by variation in tissue morphology, and electrical characteristics, namely; permittivity and conductivity across individuals [9]. Absorption of energy directed towards the body is an attractive option for use as an electromagnetic decoupling barrier, and the concept described in this paper may provide a solution. The diversity in tissue properties, which would have a greater impact on narrow band antennas, could be explored using a range of layered tissue phantoms in future studies. The indicative experimental results were obtained for an existing $\lambda / 10$ thick (at $10 \mathrm{GHz}$ ) FSS absorber that works over a $108 \%$ bandwidth at frequencies much higher than the ISM medical band. Therefore for wearable applications it would be necessary to scale up the dimensions of the periodic array, but the absorber thickness could be significantly reduced to meet the much smaller bandwidth requirements of $\approx 4 \%$ at $2.45 \mathrm{GHz}$. In conjunction with this, a further reduction in the physical thickness is possible by employing a flexible metal backed high permittivity substrate to create the thin FSS absorber, which if fully integrated with the antenna would provide a compact solution for next generation wireless systems.

N. McGuigan, G. Conway, R. Cahill, and D. Zelenchuk (The Institute of Electronics, Communications and Information Technology (ECIT), Queen's University Belfast, Northern Ireland Science Park, Queen's Road, Queen's Island, Belfast BT3 9DT, Northern Ireland, UK)

\section{S. Zabri (Universiti Teknikal Malaysia, 76100 Durian Tunggal, Melaka, Malaysia)}

E-mail: r.cahill@qub.ac.uk

\section{References}

1. Costa, F., Monorchio, A. and Manara, G.: 'Analysis and design of ultra thin electromagnetic absorbers comprising resistively loaded high impedance surfaces', IEEE Trans. Antennas Propag., 2010, 58, (5), pp. 1551-1558, doi: 10.1109/TAP.2010.2044329

2. Shang, Y., Shen, Z. and Xiao, S.: 'On the design of single-layer circuit analog absorber using double-square-loop array', IEEE Trans. Antennas Propag., 2013, 61, (12), pp. 6022-6029, doi: 10.1109/TAP.2013.2280836

3. Li, M., Xiao, S., Bai., Y.-Y and Wang'., B.-Z.: 'An ultrathin and broadband radar absorber using resistive FSS," IEEE Antennas Wirel. Propag. Lett., 2012, 11, pp. 748-751, doi: 10.1109/LAWP.2012.2206361

4. Zabri, S. N., Cahill, R. and Schuchinsky, A.: 'Compact FSS absorber design using resistively loaded quadruple hexagonal loops for bandwidth enhancement', Electron. Lett., 2015, 51, (2), pp. 162-164, doi: 10.1049/el.2014.3866

5. Zabri, N., Cahill, R. and Schuchinsky, A.: 'Polarisation independent resistively loaded frequency selective surface absorber with optimum oblique incidence performance', IET Microwaves, Antennas Propag., 2014, 8, (14), pp. 1198-1203, doi: 10.1049/iet-map.2014.0124

6. Batchelor, J. C., Parker, E. A., Miller, J. A., Sanchez-Romaguera, V. and Yeates, S. G.: 'Inkjet printing of frequency selective surfaces', Electron. Lett., 2009, 45, (1), pp. 7-8, doi: 10.1049/el:20092713

7. Zabri, S., Cahill, R., Conway, G., and Schuchinsky, A.: 'Inkjet printing of resistively loaded FSS for microwave absorbers' Electron. Lett., 2015, vol. 51, (2), pp. 162-164, doi: 10.1049/el.2015.0696

8. Novacentrix, "Printed Electronics Tools and Materials'. Available at www.novacentrix.com/, accessed August 2017

9. Gabriel, C.:'Compilation of the Dielectric Properties of Body Tissues at RF and Microwave Frequencies, Report N.AL/OE-TR- 1996-0037,' Occupational and environmental health directorate, Radiofrequency Radiation Division, Brooks Air Force Base, Texas (USA), 1996. 